\title{
Silicone stents, the rigid bronchoscope, and the standard of care in central airway stenosis
}

\author{
Hervé Dutau • Fabien Maldonado • \\ Sophie Laroumagne $\cdot$ Philippe Astoul
}

Published online: 8 February 2012

(C) Springer Science+Business Media, LLC 2012
Francois Dumon in the 1980s. Rigid bronchoscopy remains the method of choice for the treatment of both benign and malignant central airway obstruction, but significant technological advances allow for effective treatments using the flexible bronchoscope. Metallic non-covered stents are generally not recommended, except in selected patients with poor short-term prognosis.

Keywords Interventional pulmonology · Interventional bronchoscopy · Bronchoscopy · Rigid bronchoscopy . Flexible bronchoscopy - Laser - Thermocoagulation . Electrocautery · Argon plasma coagulation · Cryotherapy . Photodynamic therapy · Brachytherapy · Airway stenting . Silicone stent · Self-expandable metallic stent . Central airway obstruction · Lung cancer - Airway stenosis · Tracheal stenosis · Lung transplantation · Tracheobronchomalacia . Bronchial stenosis $\cdot$ Airway compression

\section{Introduction}

Modern bronchoscopy benefited from the work of Shigeto Ikeda, a Japanese pulmonologist, who developed flexible bronchoscopy using optic fibers [1]. This led many to regard rigid bronchoscopy as obsolete, and it was virtually abandoned in favor of flexible bronchoscopy. Few endoscopists continued to get exposed to the technique and adequate training became a rarity. However, some European physicians continued to use the rigid system for the treatment of airway diseases, among whom the father of modern therapeutic bronchoscopy, Jean-François Dumon, unanimously regarded as a pioneer in the field of interventional pulmonary medicine. He was one of the first bronchoscopists [2-5] to use laser therapy in the airway and contributed to 
standardize its utilization $[6,7]$. Another of his many contributions was the invention of a dedicated silicone stent for the trachea and bronchi [8]. Before the era of Dumon stents, the only available option for re-establishing patency of the trachea post-operatively was the Montgomery T-tube, which required a tracheostomy for placement [9]. The combination of laser debulking and stent placement in case of concurrent extrinsic compression allowed for immediate and lasting palliation of malignant central airway obstruction. These techniques allowed pulmonologists to treat central airway diseases formerly considered treatable only via extensive and often prohibitively dangerous surgical procedures.

\section{Available techniques in therapeutic bronchoscopy}

The rigid bronchoscope

The rigid bronchoscope (RB) is an invaluable tool in interventional bronchoscopy [10-12]. Although requiring general anesthesia, rigid bronchoscopy allows for adequate ventilation of the patient through a side port, efficient suctioning of blood, secretions, pus, and smoke via large suction catheters, and the use of various instruments (laser probes, cryoprobes, rigid forceps, etc.) alongside the telescope $[13 \bullet]$.

A variety of therapeutic interventions are possible including dilation of stenoses or extrinsic compressions and quick mechanical coring and debulking of endoluminal tumors using the distal sharp bevel [14]. The rigid bronchoscope is the instrument of choice in cases of acute respiratory failure secondary to endoluminal obstruction as it allows for rapid procedures while maintaining airway patency and adequate ventilation. Due to obvious anatomic limitations, its use is not suitable for upper lobe diseases. Rigid bronchoscopy is required for silicone stent placement using a dedicated rigid loading system.

\section{The flexible bronchoscope}

Treatment of central airway obstructions with the exclusive use of a flexible bronchoscope (FB) is not generally preferred, particularly in the case of tracheal lesions. The small working channel may not allow for adequate suction of secretions or blood in severe cases. In addition, flexible biopsy forceps have a smaller diameter that only permits removal of small tumoral fragments at a time, hence leading to long and fastidious procedures, an obvious shortcoming in case of respiratory emergencies [1]. Metallic snares or baskets have been developed in order to remove larger pieces of tumors or foreign bodies, but remain generally inferior to rigid bronchoscopy techniques [13•]. Rigid and flexible bronchoscopy should be regarded as complementary techniques and used concurrently during these procedures. The easy maneuverability of flexible bronchoscopes allows thorough exploration and clearing of the peripheral airways. In addition, FB is the only tool available for the treatment of upper lobes obstruction. A variety of techniques (laser, thermocoagulation, argon plasma coagulation, and cryoprobes) can be used.

\section{Ablative techniques}

Among the traditional ablative techniques, laser was the first technique used by pulmonologists [2-7]. Other ablative techniques have since become available to thoracic endoscopists such as thermocoagulation, argon plasma coagulation, cryotherapy, photodynamic therapy, and brachytherapy. All these techniques have their own advantages and disadvantages and have been reviewed elsewhere $[15 \bullet, 16,17,18]$.

\section{Airway stents}

The main purpose of tracheal and bronchial stents is to restore patency of the airway to a caliber as close to normal as possible. Any symptomatic endoluminal pathology associated with a significant reduction in airway luminal diameter (greater than 50\%) may be an indication for a silicone airway stent $[19,20 \bullet \cdot$.

Five major indications have been established [20••]:

1- Extrinsic compression from tumors or lymph nodes.

2- Stabilization of airway patency after endoscopic resection of intraluminal cancer.

3- Treatment of benign strictures.

4- Stabilization of collapsing airways (malacia and polychondritis).

5- Treatment of fistulas (eg, stump dehiscences or tracheoesophageal fistulas).

In life-threatening situations there are no absolute contraindications. However, other techniques should be considered before stent placement. Endoluminal tumors should be treated initially by laser resection, for example, and a stent should only be placed if still deemed necessary. The treatment of benign lesions requires particular caution, as stents may be harmful in the long run, even if early benefit is often noted [20••]. In general, only removable stents should be used for these indications unless a multidisciplinary team has determined inoperability $[20 \bullet \cdot$.

Airway stents are generally divided into two types: silicone and metallic stents $[20 \bullet \bullet$. Metallic stents will not be mentioned further in this article but we recommend an excellent recent review for interested readers $[20 \bullet \bullet$. 
Different types of silicone stents

- The Dumon stent (Tracheobronxane, Novatech, La Ciotat, France) remains the reference, as it is the most commonly placed stent worldwide. This airway stent has a simple design consisting of a silicone tube with small studs on the external surface to reduce migration [8]. They have become, de facto, the gold standard for the endoscopic treatment of benign and malignant stenoses [20••]. There are two specific designs: straight and Y-shaped (for disease involving the carina) [21]. Stents are available in various lengths and diameters to accommodate both pediatric [22] and adult anatomy. The largest available external diameter is $20 \mathrm{~mm}$. For irregularly shaped stenoses (ie, those with markedly reduced central airway caliber as compared to the extremities), specialized hourglass-shaped stents are available [23]. These stents are particularly useful in cases of short benign tracheal disease. Currently available stents are either made of transparent silicone (non-radioopaque) or made of silicone melted with barium sulfate (white color, radio-opaque). The new generation of transparent Dumon silicone stents (Tracheobronxane, Novatech, La Ciotat, France) will have radiopaque gold markers embedded in the external studs. The transparent Dumon stent allows for the visualization of the underlying mucosa during placement. Dumon stents should be inserted using a dedicated rigid bronchoscope. The commercialized introducer set includes a loading tool and a pusher. Dumon stents can be repositioned, removed, or replaced at any time with ease using standard grabbing rigid forceps. On-site modification of these stents is technically possible [24]. The major complications reported with silicone stents include migration $(9.5 \%)$, granuloma formation $(7.9 \%)$, obstruction secondary to secretions (3.6\%) [25], and bacterial overgrowth [26]. Migration is most frequently the result of undersized stents respective to airway diameter or, alternatively, due to tumor involution secondary to treatment. This complication is rarely fatal and presents clinically as new symptoms of cough or dyspnea. It is managed easily by removal or repositioning of the migrated stent under rigid bronchoscopy and eventual replacement with a more appropriately sized stent. Percutaneous external fixation is sometimes considered to reduce the risk of migration $[27,28]$. Granulation tissue has a tendency to form at the proximal and distal extremities of the stent and is caused by chronic inflammation. This can ultimately lead to obstruction of the stent requiring mechanical or thermal treatment (laser, electrocautery, cryotherapy). Replacement of the stent may occasionally be necessary. Mucoid impaction of the stent leading to obstruction can be quite serious and occasionally leads to life-threatening situations. This risk may be reduced with humidification of the stent via nebulization of normal saline two to three times daily while the stent is in place. Stents that get repeatedly impacted with secretions are most often associated with bacterial colonization and should generally be removed and replaced.

- The Polyflex stent (Boston Scientific, Natick, MA) is made of polyethylene threads embedded in silicone [29, 30]. The walls of these stents are thinner than those of Dumon stents, resulting in a better inner-to-outer diameter ratio. The edges of these stents are sharper and their length may vary depending on their compression state. Polyflex stents can provide a better fit for hourglass-type stenoses. However, their outer surface is slightly smoother and consequently the migration rate seems to be higher than that of Dumon stents. Little tungsten spots in the stent wall make them visible on chest radiographs. Polyflex stents are deployed using a semi-rigid tube. It cannot be overemphasized that the skills and training required for successful deployment are similar to those needed to insert Dumon stents. Modified Polyflex stents with outer struts have been used successfully in recent studies [31].

- Other CE-marked polymeric straight stents such as the Noppen stent (Reynders Medical Supply, Lennik, Belgium), which is made from Tygon [32, 33], and the Hood stents (Hood Laboratories, Pembroke, MA), which are made from silicone, may still be available but are no longer advertised [20••].

\section{Advantages and disadvantages of silicone stents}

Silicone stents are indicated for the vast majority of clinical indications whether malignant or benign, in contrast to metal stents that should for the most part be avoided in benign disease [20••]. Metal stents completely covered with silicone may be an exception. Although complications do occur with these stents, they are very rarely fatal and usually readily reversible. In fact, silicone stent removal is quite easy. These stents have a radial force sufficient to render them quite effective in extrinsic airway compression, but still can readily be manipulated and repositioned within the airway without concern [20••]. Techniques do exist to preserve ventilation to lobes covered by an endobronchial stent [24]. It is important to note that the cost of a silicone stent is significantly less than that of a metal self-expandable stent in the order of 1.5-2 times. The requirement for rigid bronchoscopy and general anesthesia for the placement of silicone stents is considered by some a distinct disadvantage; however, in our opinion this should not be considered the case. These same skills/resources are essential for the management of potential complications that may result from the insertion of metal stents. Due to pliability properties of 
the silicone stent, curvilinear conformations are not ideal indications. In these situations the stent may either fold centrally resulting in obstruction or even migrate due to a tendency to maintain its straight tubular conformation. Conditions such as tracheobronchomalacia where there is variable dimension of the airways may not always be ideally served by silicone stents with fixed diameters. The tubular structure with external studs of the Dumon stent may limit its ability to achieve complete apposition of the stent to the airway wall, leading to incomplete seal. This may be important in the case of fistulas as there is potential for a small residual leak around the stent.

\section{Standard of care of central airway stenosis}

The following sections will highlight the use of rigid bronchoscopy and silicone stents for the management of different types of airway stenoses.

\section{Malignant airway stenosis}

Bronchial obstruction is frequently encountered during the course of bronchial carcinoma. More than $30 \%$ of bronchial carcinomas present as a central airway obstruction [34].

Such obstructions may lead to specific complications that include reduced survival and decreased quality of life [35]. However, the vast majority of patients still die from general complications caused by their primary intrathoracic disease and only about $35 \%$ from local complications: severe hemoptysis, respiratory infections, or asphyxia [35]. Given that oncologic treatments do not generally result in prompt improvements in patients' symptoms [36, 37], endoscopic treatments are necessary adjuncts to the tailored management of the patients at all the stages of the disease (neoadjuvant, adjuvant, and palliative). In addition, bronchial obstruction-related complications (atelectasis, respiratory insufficiency or distress, recurrent infections) are likely to interfere with optimal oncologic treatments, such as chemotherapy or radiotherapy. Malignant airway obstruction is often classified based on the type of airway involvement [38]. Airway involvement can be intrinsic, ie, endoluminal, extrinsic (extrinsic compression), or mixed (with both endoluminal obstruction and extrinsic compression) $[12,38]$.

In summary, intrinsic involvement can be managed with debulking techniques and on occasion a stent may be placed as a bridge to chemo-radiotherapy, or alternatively as a permanent solution when the risk of local recurrence is high. Extrinsic compression without intra-luminal disease is readily treated with dilatation followed by stenting. Mixed (intrinsic and extrinsic) obstruction requires a multimodality approach with debulking and stent insertion.
Two conditions are required in order to achieve efficient debulking $[12,38]$ :

- The obstruction has to be located in the central airway (trachea, main stem bronchi, bronchus intermedius). In selected cases, lobar bronchi obstructions may be considered to be reasonable indications, though arguably the clinical impact is more limited and the procedurerelated risk is higher.

- Airway patency beyond the obstruction. Voluminous lesions, massively invading lung parenchyma, or carcinomatous lymphangitis are not considered valid indications.

The presence of functional parenchyma beyond an obstruction is sometimes difficult to appreciate before undertaking endoscopic debulking. Recent documented atelectasis, persisting radiological aeration, or persisting vascularization in the atelectatic parenchyma can represent helpful information. Endobronchial ultrasound using miniprobes can help in differentiating airway compression or infiltration [39]. PET scan can also help appreciate the extent of tumor within an area of atelectasis.

An efficient endoscopic treatment allows for oncologic treatments to be done in better conditions with reduced complications, and improve subjective respiratory symptoms, lung function [40], performance status, survival [41-44], and quality of life [45*]. Life expectancy of patients presenting with symptomatic obstruction and successfully treated endoscopically is equal to that of asymptomatic patients at equivalent stages of disease [46]. Benefit duration after stent placement is generally reported to be around 4 months before tumoral stent overgrowth [47], but can be increased with the use of effective oncologic treatments (ie, chemotherapy and/or radiotherapy) [48].

Classically, squamous cell carcinomas more frequently involve the central airways, while adenocarcinomas are generally more peripheral. Small cell carcinomas respond promptly to chemotherapy, and as such bronchoscopic treatments should be reserved to cases of acute respiratory distress as a bridge to chemotherapy and/or radiotherapy, or after failure of treatment.

Other indications for endobronchial treatment include endobronchial metastases (eg, esophageal, thyroid, renal cell carcinoma, colon, and melanoma) or alternatively lowgrade primary tumors (eg, adenoid cystic carcinomas, typical or atypical carcinoids).

Benign airway stenosis

\section{Post-intubation or post-tracheostomy tracheal stenosis}

Despite the lower incidence of post-intubation or posttracheostomy tracheal stenosis (PITTS), management of 
such conditions remains challenging. Indeed, even if surgical repair (sleeve resection) is the best definitive solution, approximately $50 \%$ of patients present with acute respiratory distress prompting emergent less invasive endoscopic treatments as a bridge to surgery or as definitive treatment in case of contraindications to surgery [49].

One can divide PITTS into two different types: the weblike PITTS (disease of the tracheal mucosa sparing the cartilaginous rings) and the complex PITTS (involving deterioration of the cartilaginous support) [50]. The web-like PITTS is generally successfully treated by radial mucosal incisions followed by mechanical dilation [51]. The rate of success is close to $90 \%$, in one to three sessions [52••]. For the complex PITTS, mechanical dilation alone is most of the time not sufficient [50]. In case of surgical contraindication, the next step would be the placement of a stent in order to maintain the long-term patency of the tracheal lumen and prevent recurrence [50].

The choice of the stent is important. Self-expandable metallic stents (SEMS) have been shown to make potentially operable PITTS inoperable because of the severe complications associated with the technique [53].

In addition, they are more difficult to remove because of the re-epithelialization of their uncovered parts. These facts prompted the FDA to publish recommendations to limit the use of SEMS in benign tracheal stenosis [54]. Metallic tracheal stents should only be considered in patients with benign airway disorders when all other treatment options (such as tracheal surgical procedures or placement of silicone stents) have been considered and not deemed possible. Using metallic tracheal stents as a bridge to other therapies is not recommended, because removal of the metallic stent can result in serious complications. If a metallic tracheal stent is the only option for a patient, insertion should be done by a physician trained or experienced in metallic tracheal stent procedures. Likewise, if removal is necessary, the procedure should be performed by a physician trained or experienced in removing metallic tracheal stents. Silicone stents are more suitable because of their easy removal and are not likely to jeopardize a future surgery. Long-term results (no recurrence after stent removal at 1 year) vary from $40 \%$ when the stent is placed for 6 months to $70 \%$ when the stent remains in place for 18 months $[50,52 \bullet, 55$, 56]. One should also take into account the fact that silicone stents require surveillance and may present complications like migrations, granulations, and/or mucus obstructions that can affect the quality of life [57]. Migration is probably the most challenging complication in this indication, with a frequency ranging from $11 \%$ to $17.5 \%$ [49], especially when the stenosis is close to the vocal cords. This can be reduced by the use of a dedicated hour-glass silicone stent [23] or by external fixation [27, 28]. Management of PITTS should be based on a multidisciplinary approach involving interventional pulmonologists, ENT and thoracic surgeons, and the choice of modality has to be based on the location of the PITTS (subglottic stenosis being more challenging), its length (more than $6 \mathrm{~cm}$ appears to be the limitation for surgical resection until tracheal replacement becomes widely available), and the clinical status of the patient. Endoscopic techniques represent, in about $50 \%$ of the cases, a very efficient treatment for PITTS, but many questions remain regarding its long-term efficacy and its impact on the quality of life when compared to surgery.

\section{Bronchial stenosis following lung transplantation (LT)}

Improvements in surgical techniques, immunosuppressive regimen, and postoperative care have resulted in markedly improved clinical outcomes, as airway complication rates have decreased, presently ranging from $5 \%$ to $30 \%$ with an associated mortality rate of 2\%-3\% [58-63].

Several endoscopic interventions may allow effective management of LT-related airway complications. Such procedures include cryoablation, laser photoresection, balloon bronchoplasty, electrocautery, brachytherapy, airway dilation using rigid bronchoscopy, and stent placement [64]. Stent placement is usually considered for bronchomalacia, bronchial stenosis, combined stenosis and malacia, or bronchial dehiscence when these conditions are responsible for respiratory symptoms, persistent decline in lung function, or post-obstructive complications such as mucus retention and/ or infection. Although many studies have previously described management of LT-related airway complications with SEMS, little data are available with regard to the use of silicone stents for this indication. Stent placement can result in mucosal ischemia and re-stenosis is a common finding. While the overall results (survival and clinical outcome) favor stent placement, a high rate of stent-related problems such as scarring, mucus plugging, bacterial colonization, and migration have to be accepted with currently available stents. It is advisable to select a stent that can be removed if necessary without causing further tissue damage. Recently, our group has published a retrospective study on Dumon stent placement in anastomotic stenosis after lung transplantation [65*0]. These stents could be removed definitively in $70 \%$ of the patients without further recurrence $[65 \cdot \bullet$.

\section{Tracheobronchomalacia}

Adult tracheobronchomalacia (TBM) is traditionally described as weakness of the tracheal or bronchial wall from softening of the supporting cartilage and hypotonia of myoelastic elements [66, 67]. The congenital form of TBM is well described in the pediatric literature [68-70], and may be associated with other congenital conditions. The adult forms of TBM are idiopathic or acquired during the course of other illnesses, and are disorders of middle-aged 
and older persons. During recent years, various stents have been used for these indications [67, 70]. It is difficult, however, to draw conclusions about the efficacy of endoluminal stents pertaining only to TBM and excessive dynamic airway collapse based on available data [71]. Pulmonary function tests may improve significantly after stenting of various causes of central airway obstruction, including malacia. More than one stent may be required if the symptoms persist after stenting, presumably because of distal migration of choke points [72, 73]; therefore, most endoscopists have become reluctant about the use of permanent stent placement for malacia. The choke region can be identified with new techniques [74], but any procedure may simply shift the choke region toward the periphery and there are no clear predictors of success. A trial and error approach can be considered and a temporary stent placed in order to determine whether patients may benefit from this internal splinting. If they do, they may be considered for definitive surgery using external stenting techniques, or, alternatively, the stent may be left in place if tolerated (or if surgery is deemed contraindicated or not technically feasible) [75]. If not, the stent is removed and physiotherapy and CPAP is recommended.

\section{Conclusions}

The modern management of central airway obstruction includes a variety of bronchoscopic techniques. Stents have been used increasingly for this indication and are generally safe and easily placed by trained proceduralists. Rigid bronchoscopy and silicone stents remain the most widely used modality and have been considered the standard of care, although self-expandable stents deployed via flexible bronchoscopy have been increasingly used as well. Non-covered metallic stents should not be used in benign diseases.

Disclosure No potential conflicts of interest relevant to this article were reported.

\section{References}

Papers of particular interest, published recently, have been highlighted as:

- Of importance

•- Of major importance

1. Vachani A, Sterman DH. Bronchoscopy. In: Albert RK, Spiro SG, Jett JR, editors. Clinical respiratory medicine. 3rd ed. Philadelphia: Mosby Elsevier; 2008. p. 177-96.
2. Toty L, Personne C, Colchen A, Vourc'h G. Bronchoscopic management of tracheal lesions using the YAG laser. Thorax. 1981;36:175-8.

3. Dumon JF, Reboud E, Garbe L, et al. Treatment of tracheobronchial lesions by laser photoresection. Chest. 1982;81:278-84.

4. Unger M. Bronchoscopic utilisation of the Nd YAG laser for obstructive lesions of the trachea and bronchi. Surg Clin N Amer. 1984;64:931-8.

5. Kvale PA, Eichenhorn MS, Radke JR, Miks V. Yag laser photoresection of lesions obstructing the central airways. Chest. 1985;87:283-8.

6. Dumon JF, Meric B, Bourcereau J, et al. Principles for safety in application of Nd: YAG laser in bronchology. Chest. 1984;86:27884.

7. Dumon JF, Shapshay S, Bourcereau J, et al. Principles for safety in application of Nd-YAG laser in bronchology. Chest. 1984;86:1638.

8. Dumon JF. A dedicated tracheobronchial stent. Chest. 1990;97:328-32.

9. Montgomery WW. Silicone tracheal canula. Ann Otol (St Louis). 1980;89:521-9.

10. Bolliger CT, Mathur PN, Beamis JF, et al. ERS/ATS statement on interventional pulmonology. European Respiratory Society/American Thoracic Society. Eur Respir J. 2002;19:356-373.

11. Ernst A, Silvestri GA, Johnstone D. Interventional pulmonary procedures. Guidelines from the American College of Chest Physicians. Chest. 2003;123:1693-717.

12. Ernst A, Feller-Kopman D, Becker H, Mehta AC. Central airway obstruction: state of the art. Am J Respir Crit Care Med. 2004;169:1278-97.

13. • Plekker D, Koegelenberg CFN, Bolliger CT. Different techniques of bronchoscopy. In: Strausz J, Bolliger CT (eds). Interventional pulmonology. Eur Respir Mon. 2010;48:1-17. This is a recent exhausting review on all the technical considerations of bronchoscopy.

14. Seijo LM, Sterman DH. Interventional pulmonology. N Engl J Med. 2001;344:740-9.

15. - Dutau H, Breen DP. Endobronchial laser treatment: an essential tool in therapeutic bronchoscopy. In: Strausz J, Bolliger CT. Interventional pulmonology. Eur Respir Monogr. 2010;48:149-160. Exhaustive review on laser applications in the airway.

16. Bolliger CT, Sutedja TG, Strausz, Freitag L. Therapeutic bronchoscopy with immediate effect: laser, electrocautery, argon plasma coagulation and stents. Eur Respir J. 2006;27:1258-71.

17. Morgan RK, Ernst A. Cryosurgery. In Strausz J, Bolliger CT. Interventional pulmonology. Eur Respir Monogr. 2010;48:161172.

18. Michailidou I, Becker HD, Eberhardt R. Bronchoscopic high-doserate brachyterapy. In: Strausz J, Bolliger CT. Interventional pulmonology. Eur Respir Monogr. 2010;48:173-189.

19. De Wood, Liu YH, Vallieres E. Airway stenting for malignant and benign tracheobronchial stenosis. Ann Thorac Surg. 2003;76:16774.

20. •• Freitag L. Airway stents. In: Strausz J, Bolliger CT. Interventional pulmonology. Eur Respir Mon. 2010;18:190-217. Exhaustive review on airway stenting with all the existing stents and for all the indications.

21. Dutau H, Toublanc B, Lamb C, et al. Use of the Dumon Y-stent in the management of malignant diseases involving the carina: a retrospective review of 86 patients. Chest. 2004;126:951-8.

22. Fayon M, Donato L, de Blic J, et al. The French experience of silicone tracheobronchial stenting in children. Pediatr Pulmonol. 2005;39:21-7.

23. Vergnon JM, Costes F, Polio JC. Efficacy and tolerance of anew silicone stent for the treatment of benign tracheal stenosis: preliminary results. Chest. 2000;118:422-6. 
24. Breen DP, Dutau H. On-site customization of silicone stents: towards optimal palliation of complex airway conditions. Respiration. 2009;77:447-53.

25. Dumon JF, Cavaliere S, Diaz-Jimenez JP, et al. Seven years experience with the Dumon prosthesis. J Bronchol. 1996;3:6-10.

26. Noppen M, Pierard D, Meysman M, et al. Bacterial colonization of central airway after stenting. Am J Respir Crit Care Med. 1999;160:672-7.

27. Miwa K, Takamori S, Hayashi A, et al. Fixation of silicone stents in the subglottic trachea: preventing stent migration using a fixation apparatus. Ann Thorac Surg. 2004;78:2188-90.

28. Colt H, Harrel J, Neuman T, et al. External fixation of subglottic tracheal stents. Chest. 1994;105:1653-7.

29. Wassermann K, Koch A, Muller-Ehmsen J, et al. Clinical and laboratory evaluation of a new thin-walled self-expanding tracheobronchial silicone stent: progress and pitfalls. J Thorac Cardiovasc Surg. 1997;114:527-34.

30. Bolliger CT, Wyser C, Wu X, et al. Evaluation of a new selfexpandable silicone stent in an experimental tracheal stenosis. Chest. 1999;115:496-501.

31. Bolliger CT, Breitenbuecher A, Brutsche M, et al. Use of studded Polyflex stents in patients with neoplastic obstructions of the central airways. Respiration. 2004;71:83-7.

32. Noppen M, Dhaese J, Meysman M, et al. A new screw-thread tracheal endoprosthesis. J Bronchol. 1996;3:22-6.

33. Noppen M, Meysman M, Claes I, et al. Screw-thread vs Dumon endoprosthesis in the management of tracheal stenosis. Chest. 1999;115:532-5.

34. Minna JD, Higgins GA, Glatstein EJ. Cancer of the lung. In: De Vita VT, Hellman S, Rosenberg SA, editors. Cancer principles and practice of oncology. 3rd ed. Philadelphia: JB Lippincott Co; 1989. p. 591-705.

35. Stanley K. Pronostic factors for survival in patients with inoperable lung cancer. JNCI. 1980;65:25-32.

36. Parrat E, Pujol JL, Gautier V, et al. Chest tumor response during lung cancer chemotherapy. Computed tomography versus fiberoptic bronchoscopy. Chest. 1993;103:1495-510.

37. Cherry KG, Moran E, Sassoon CS, et al. Effect of radiation therapy on bronchial obstruction due to bronchogenic carcinoma. Chest. 1989;95:582-4.

38. Vergnon JM. Les traitements endoscopiques du cancer bronchique. Rev Mal Respir. 2008;25:3S160-6.

39. Herth F, Ernst A, Schulz M, et al. Endobronchial ultrasound reliably differentiates between airway infiltration and compression by tumor. Chest. 2003;123:458-62.

40. Mohsenifar Z, Jasper A, Koerner S. Physiologic assessment of lung function in patients undergoing laser photoresection of tracheobronchial tumors. Chest. 1988;93:65-9.

41. Eichenhorn MS, Kvale PA, Miks VM, et al. Initial combination therapy with yag laser photoresection and irradiation for inoperable non small cell carcinoma of the lung. Chest. 1986;89:782-5.

42. Desai SJ, Mehta AC, Medendorp SV, et al. Survival experience following $\mathrm{Nd}$ Yag laser photoresection for primary bronchogenic carcinoma. Chest. 1988;94:939-44.

43. Ross DJ, Mohsenfar Z, Koerner SK. Survival characteristics after Nd-Yag laser photoresection in advanced lung cancer. Chest. 1990;98:581-5.

44. Macha HN, Becker KO, Kemmer HP. Pattern of failure and survival in endobronchial laser resection. A match pair study. Chest. 1994;105:1668-72.

45. - Oviatt PL, Stather DR, Michaud G, et al. Exercise capacity, lung function, and quality of life after interventional bronchoscopy. J Thorac Oncol. 2011;6:38-42. One of the rare studies focused on quality of life in interventional pulmonology.

46. Chhajed PN, Baty F, Pless M, et al. Outcome of treated advanced non-small cell lung cancer with and without central airway obstruction. Chest. 2006;130:1803-7.
47. Vergnon J-M, Costes F, Bayon MC, et al. Efficacy of tracheal and bronchial stent placement on respiratory functional tests. Chest. 1995; 107:741-6.

48. Han CC, Prasetyo D, Wright GM. Endobronchial palliation using $\mathrm{Nd}$ :YAG laser is associated with improved survival when combined with multimodal adjuvant treatments. J Thorac Oncol. 2007;2:59-64.

49. Baignee PE, Marquette CH, Ramon P, et al. Endoscopic treatment of post-intubation tracheal stenosis. A propos of 58 cases. Rev Mal Respir. 1995;12:585-92.

50. Brichet A, Verkindre C, Dupont J, et al. Multidisciplinary approach to management of post-intubation tracheal stenoses. Eur Respir J. 1999;13:888-93.

51. Mehta AC, Lee FY, Cordasco EM, et al. Concentric tracheal and subglottic stenosis. Management using Nd-YAG laser for mucosal sparing followed by gentle dilatation. Chest. 1993;104:673-7.

52. • Galluccio G, Lucantoni G, Battistoni P, et al. Interventional endoscopy in the management of benign tracheal stenoses: definitive treatment at long-term follow up. Eur J Cardiothorac Surg. 2009;35:429-433. Large series of tracheal stenosis treated with silicone stent, with a $70 \%$ of stenosis resolution after stent removal.

53. Gaissert HA, Grillo HC, Wright CD, et al. Complication of benign tracheobronchial strictures by self-expanding metal stents. J Thorac Cardiovasc Surg. 2003;126:744-7.

54. FDA. U.S. Food and Drug Administration. FDA Public Health Notification: Complications from metallic tracheal stents in patients with benign airway disorders. July 29, 2005.www.fda.gov/ MedicalDevices/Safety/AlertsandNotices/PublicHealthNotifications/ UCM062115.

55. Martinez-Ballarin JL, Diaz-Jimenez JP, Castro MJ, Moya JA. Silicone stents in the management of benign tracheobronchial stenoses. Tolerance and early results in 63 patients. Chest. 1996;103:626-9.

56. Cavaliere S, Bezzi M, Toninelli C, et al. Management of postintubation tracheal stenoses using the endoscopic approach. Monaldi Arch Chest Dis. 2007;67:71-2.

57. Bolliger CT, Probst R, Tschopp K, et al. Silicone stents in the management of inoperable tracheobronchial stenoses. Indications and limitations. Chest. 1993;104:1653-9.

58. Mulligan MS. Endoscopic management of airway complications after lung transplantation. Chest Surg Clin N Am. 2001;11:907-15.

59. Alvarez A, Algar J, Santos F, et al. Airway complications after lung transplantation: a review of 151 anastomoses. Eur J Cardiothorac Surg. 2001;19:381-7.

60. Shennib H, Massard G. Airway complications in lung transplantation. Ann Thorac Surg. 1994;57:506-11.

61. Colt HG, Janssen JP, Dumon JF, et al. Endoscopic management of bronchial stenosis after double lung transplantation. Chest. 1992;102:10-6.

62. Ruttmann E, Ulmer H, Marchese M, et al. Evaluation of factors damaging the bronchial wall in lung transplantation. J Heart Lung Transplant. 2005;24:275-81.

63. de Hoyos AL, Patterson GA, Maurer JR, et al. Pulmonary transplantation. Early and late results. The Toronto Lung Transplant Group. J Thorac Cardiovasc Surg. 1992;103:295-306.

64. Santacruz JF, Mehta AC. Airway complications and management after lung transplantation: ischemia, dehiscence, and stenosis. Proc Am Thorac Soc. 2009;6:79-93.

65. •• Dutau H, Cavailles A, Sakr L, et al. Silicone stent placement for the management of anastomotic airway complications in lung transplant recipients: a retrospective study: short and long terms outcome. J Heart Lung Transplant. 2010;29:658-664. First study on silicone stent in this indication, showing a $70 \%$ rate of success after stent removal.

66. Baxter JD, Dunbar JS. Tracheomalacia. Ann Otol Rhinol Laryngol. 1963;72:1013-23. 
67. Murgu SD, Colt HG. Tracheobronchomalacia and excessive dynamic airway collapse. Respirology. 2006;11(4):388-406.

68. Finder JD. Primary bronchomalacia in infants and children. J Pediatr. 1997;130:59-66.

69. Masters IB, Chang AB, Patterson L, et al. Series of laryngomalacia, tracheomalacia, and bronchomalacia disorders and their associations with other conditions in children. Pediatr Pulmonol. 2002;34:189-95.

70. Carden KA, Boiselle PM, Waltz DA, Ernst A. Tracheomalacia and tracheobronchomalacia in children and adults: an in-depth review. Chest. 2005;127:984-1005.

71. Ernst A, Odell DD, Michaud G, et al. Central airway stabilization for tracheobronchomalacia improves quality of life in patients with chronic obstructive pulmonary disease. Chest. 2011 Aug 25. [Epub ahead of print].

72. Miyazawa T, Miyazu Y, Iwamoto Y, et al. Stenting at the flowlimiting segment in tracheobronchial stenosis due to lung cancer. Am J Respir Crit Care Med. 2004;169:1096-102.

73. Ernst A, Majid A, Feller-Kopman D, et al. Airway stabilization with silicone stents for treating adult tracheobronchomalacia: a prospective observational study. Chest. 2007;132:609-16.

74. Murgu SD, Colt HG. Complications of silicone stent insertion in patients with expiratory central airway collapse. Ann Thorac Surg. 2007;84:1870-7.

75. Murgu SD, Colt HG. Tracheobronchoplasty for severe tracheobronchomalacia. Chest. 2009;135:1403-4. 